Research article Open Access

\title{
HER2 gene status in primary breast cancers and matched distant metastases
}

\author{
Coya Tapia ${ }^{1}$, Spasenija Savic ${ }^{1}$, Urs Wagner ${ }^{2}$, René Schönegg ${ }^{3}$, Hedvika Novotny ${ }^{1}$, Bruno Grilli', \\ Michelle Herzog1', Audrey DeVito Barascud1', Inti Zlobec ${ }^{1}$, Gieri Cathomas', Luigi Terracciano1, \\ Georg Feichter ${ }^{1}$ and Lukas Bubendorf ${ }^{1}$
}

\author{
1 University Department of Pathology of Basel and Baselland, Institute for Pathology, Schönbeinstrasse 40, Basel, 4003, Switzerland \\ 2Viollier AG, Division of Histopathology and Cytology, Jacob Burckhardt-Strasse 86, Basel, 4002, Switzerland \\ ${ }^{3}$ Cantonal Hospital, Institute for Pathology, Rorschacher Strasse 95, St Gallen, 9007, Switzerland \\ ${ }_{4}^{4}$ University Department of Pathology of Basel and Baselland, Cantonal Institute for Pathology, Mühlemattstrasse 11, Liestal, 4410, Switzerland \\ Corresponding author: Lukas Bubendorf, lbubendorf@uhbs.ch
}

Received: 18 Jan 2007 Revisions requested: 19 Mar 2007 Revisions received: 18 Apr 2007 Accepted: 19 May 2007 Published: 19 May 2007

Breast Cancer Research 2007, 9:R31 (doi:10.1186/bcr1676)

This article is online at: http://breast-cancer-research.com/content/9/3/R31

(c) 2007 Tapia et al.; licensee BioMed Central Ltd.

This is an open access article distributed under the terms of the Creative Commons Attribution License (http://creativecommons.org/licenses/by/2.0), which permits unrestricted use, distribution, and reproduction in any medium, provided the original work is properly cited.

\begin{abstract}
Introduction The status of the gene encoding human EGF-like receptor 2 (HER2) is an important prognostic and predictive marker in breast cancer. Only breast cancers with HER2 amplification respond to the targeted therapy with trastuzumab. It is controversial to what degree the primary tumour is representative of distant metastases in terms of HER2 status. Discrepancies in HER2 status between primary tumours and distant metastases have been described, but their reasons remain unclear. Here, we compared HER2 status on cytological specimens of distant metastases with the result from the primary carcinomas, and explored the prevalence of and the reasons for discrepant results.
\end{abstract}

Methods HER2 status was determined by fluorescence in situ hybridisation. HER2 gene amplification was defined as a HER2/ chromosome 17 signal ratio of 2 or more. HER2 results from cytological specimens of matched distant metastases were compared with the results from the corresponding primary tumours ( $n=105$ patients). In addition, lymph node metastases were analysed in 31 of these patients.
Results HER2 amplification was found in $20 \%$ of distant metastases. HER2 status was discordant between the primary tumour and distant metastasis in $7.6 \%$ of the 105 patients. Reevaluation revealed that in five patients $(4.7 \%)$, discrepancies were due to interpretational difficulties. In two of these patients, focal amplification had initially been overlooked as a result of heterogeneity in the primary tumours or in the metastases, respectively. A further three patients had borderline amplification with a ratio close to 2 . Discrepancy remained unexplained in three patients (2.9\%).

Conclusion HER2 gene status remains highly conserved as breast cancers metastasise. However, discrepant results do occur because of interpretational difficulties and heterogeneity of HER2 amplification. Cytological specimens from distant metastases are well suited for HER2 fluorescence in situ hybridisation analysis.

\section{Introduction}

The HER2 oncogene encodes a transmembrane tyrosine kinase (human EGF-like receptor 2) located on chromosome $17 q 21[1,2]$. HER2 protein belongs to the epidermal growth factor family [3] and is important for cell differentiation, adhesion and motility [4]. HER2 gene amplification and protein overexpression exists in about $20 \%$ of breast cancers $[5,6]$ and is linked to a poor prognosis [7]. From a clinical point of view, HER2 receptor has become important as a target for antibody-based therapy with trastuzumab (Herceptin ${ }^{\circledR}$ ) [8]. Trastuzumab was originally approved for the treatment of metastatic HER2-positive breast cancers because of a significant survival benefit when given in combination with paclitaxel [911]. More recently, adjuvant treatment of primary, HER2-posi-

CEP17 = centromere probe of chromosome $17 ; \mathrm{Cl}=$ confidence interval; $\mathrm{DAPI}=4$ ',6-diamidino-2-phenylindole; FISH = fluorescence in situ hybridisation; HER2 = gene encoding human EGF-like receptor 2; SSC = saline sodium citrate; TMA = tissue microarray. 
tive breast cancers with trastuzumab has been shown to improve patient outcome markedly [12]. Thus, determination of HER2 status in every breast cancer patient to select for adjuvant treatment with trastuzumab is becoming a standard worldwide. There has been much debate on how to test HER2 status. Other than fluorescence in situ hybridisation (FISH), immunohistochemistry is liable to technical and interpretational variability [13-15]. Accordingly, it has been shown that response to trastuzumab is strongly associated with HER2 gene status irrespective of protein expression determined by immunohistochemistry $[16,17]$. Importantly, no standardised immunocytochemical assay is available for cytological specimens. For these reasons, testing the HER2 gene status by $\mathrm{FISH}$ is now widely regarded as the gold standard [18].

HER2 status is commonly determined in the primary tumour, because biopsies from metastasised lesions are not always available. In three previous FISH studies on 12 to 68 patients, the prevalence of a discrepant result between the primary breast cancer and the distant metastasis ranged from $0 \%$ to $22.2 \%$ [19-23].

Because of the controversial data and the therapeutic importance of HER2 testing, we compared the HER2 status in a large series of primary breast cancers and their matched distant metastases by FISH. In addition, we attempted to elucidate reasons for these discrepancies.

Our results demonstrate that discrepancies in HER2 gene status between primary breast cancers and matched metastases do occur and may be related to technical and interpretational difficulties.

\section{Materials and methods Patients and specimens}

A consecutive series of 105 cytological specimens from distant metastases of breast cancer samples was obtained from the institute for Pathology of the University Hospital Basel ( $n=$ 92), the Cantonal Institute for Pathology in Liestal $(n=7)$ and the Cantonal Institute for Pathology in St Gallen $(n=6)$, Switzerland. The specimens had been collected between the years 1999 and 2006. Data on pT (tumour size and invasion) and pN (lymph-node status) categories were obtained from the original pathology reports. Because systematic histological grading according to Bloom Richardson Elston [24] was not available in all patients, we used the nuclear grade (1 to 3 ) that was described in all cases. A tissue block containing representative tissue from each of the primary breast cancers was retrieved from the archives of the above-listed institutes as well as from Viollier AG, Division of Histopathology, Basel. A tissue microarray (TMA) was constructed from these original blocks as described previously [25]. The TMA included 87 primary breast cancers and 38 matched lymph node metastases that had not been previously analysed by FISH. One tissue core with a diameter of $0.6 \mathrm{~mm}$ was sampled from each of the pri- mary tumours. Because lymph node metastases can be missed on the TMA cores as a result of focal distribution we sampled three TMA cores of each positive lymph node. Eleven primary tumours and seven lymph nodes had no informative results on the TMA because of missing tissue, no tumour tissue or unsuccessful hybridisation. In these cases we analysed a routine tissue sections of the primary tumour by FISH. Whole-tissue section analysis was performed in a further six tumours that were not represented on the TMA. In a further 12 primary tumours, FISH results were already available from previous analyses that had been performed in the diagnostic setting. The characteristics of all 105 patients and their primary tumour are summarised in Table 1. The sites of the metastases are shown in Table 2. The median time between breast cancer diagnosis and the cytological diagnosis of the distant metastases was 66 months (range 0 to 254 months). Eight patients had synchronous metastases (interval less than 1 month). Information on the treatment between the resection of the primary tumour and the occurrence of distant metastases was not available in this study. However, standard adjuvant treatment was performed in accordance with the guidelines of the consensus conference of St Gallen, 2005 [26]. None of the patients with discrepant HER2 results received trastuzumab therapy.

Table 1

Characteristics of patients and their primary breast cancers

\begin{tabular}{ll}
\hline Characteristic & $n$ (percentage) \\
\hline Age (years) & 57.5 \\
Mean & $26-85$ \\
Range & \\
Tumour size (cm) & $28(26.6)$ \\
$\leq 2$ & $57(54.3)$ \\
$>2 \leq 5$ & $9(8.6)$ \\
$>5$ & $11(10.5)$ \\
Not available & \\
Histological type & $82(78.1)$ \\
Ductal & $12(11.4)$ \\
Lobular & $10(9.5)$ \\
Ductulo-lobular & $1(1)$ \\
Medullary & \\
Nuclear grade & $7(6.7)$ \\
1 & $41(39)$ \\
2 & $55(52.4)$ \\
3 & $2(1.9)$ \\
Not available & \\
\hline
\end{tabular}


Table 2

\begin{tabular}{lll}
\hline Localisation of the metastases & & \\
\hline Localisation & $n$ & Percentage \\
\hline Ascites & 3 & 2.8 \\
Liver & 4 & 3.8 \\
Lung & 9 & 8.6 \\
Distant lymph nodes & 3 & 2.9 \\
Pericardium & 1 & 1.0 \\
Pleura & 74 & 70.5 \\
Skin/soft tissue & 3 & 2.8 \\
Central nervous system & 8 & 7.6 \\
Total & 105 & 100 \\
\end{tabular}

\section{Specimen pretreatment and FISH assay}

For FISH analysis of the cytological specimens, the most representative routine Papanicolaou-stained smears or cytospins were used. A hybridisation target area of $22 \mathrm{~mm} \times 22 \mathrm{~mm}$ was selected on the basis of high cellularity. This area was first marked with a waterproof pen. In rare tumour cells, the exact locations of the tumour cells in this marked area were saved with relocalisation software (Mark\&Find Module; Carl Zeiss Vision $\mathrm{GmbH}$, Halbermoos, Germany) linked to an automated stage (type 00-24-473-0000; Carl Zeiss AG, Oberkochen Germany) on a Zeiss Axioplan 2 epifluorescence microscope (Zeiss, Jena, Germany) before hybridisation. We used this system to relocate the tumour cells after hybridisation in 34 cases (32.4\%). The commercially available dual-colour FISH probe PathVysion ${ }^{\circledR}$ was from Abbott/Vysis (Downers Grove, IL, USA). The probes were provided at no charge for those patients in whom FISH analysis was done for research purpose only. It included fluorescence-labelled DNA probes for the HER2 gene locus (SpectrumOrange) and centromere 17 (CEP17, SpectrumGreen).

FISH was performed, with small modifications, as recommended by the manufacturer. The smears were washed briefly in xylene until the coverslip could be removed. After that they were washed in fresh xylene twice, 5 minutes per wash. Then they were immersed twice in 100\% ethanol for 5 minutes and soaked in $2 \times$ saline sodium citrate (SSC) buffer for 1 minute at room temperature $\left(20-24^{\circ} \mathrm{C}\right)$. Subsequently they were incubated in $0.5 \mathrm{mg} / \mathrm{ml}$ pepsin solution in $10 \mathrm{mM}$ hydrochloric acid for 10 minutes at $37^{\circ} \mathrm{C}$, followed by a wash in phosphatebuffered saline for 5 minutes. The smears were washed twice in Carnoy's fixative for 5 minutes, each time at room temperature, and dehydrated by immersion in $70 \%$ ethanol solution for 5 minutes, also at room temperature, followed by immersion in $80 \%$ and $100 \%$ ethanol. After that the slides were denatured for 10 minutes in $70 \%$ formamide $/ 2 \times \mathrm{SSC}$ at $73^{\circ} \mathrm{C}$. Finally, the smears were dehydrated in a series of $70 \%, 85 \%$ and
$100 \%$ ethanol ( 2 minutes per solution), then dried in an oven at 37 to $45^{\circ} \mathrm{C}$ for 2 minutes.

After denaturation at $73^{\circ} \mathrm{C}$ for 5 minutes, the probe hybridisation mix was applied to the smears. The smears were then covered with coverslip ( $22 \mathrm{~mm} \times 22 \mathrm{~mm}$ ), sealed with rubber cement and incubated overnight in a humid chamber at $37^{\circ} \mathrm{C}$. Next morning, the slides were washed in $0.4 \times \mathrm{SSC} / 0.3 \%$ Nonidet $\mathrm{P} 40$ at $73^{\circ} \mathrm{C}$ for 2 minutes. Finally, they were rinsed twice in $2 \times \mathrm{SSC} / 0.1 \%$ Nonidet P40 for 2 minutes and then air-dried. 4',6-Diamidino-2-phenylindole (DAPI II) was added for counterstaining.

FISH on the histological specimens of the primary tumours was performed as described previously [17]. We analysed the slides with a Zeiss Axioplan 2 epifluorescence microscope (Zeiss, Jena, Germany) equipped with filter sets for DAPI, SpectrumOrange and SpectrumGreen at a magnification of $\times 1,000$. HER2 amplification was defined as a HER2/CEP17 ratio of 2.0 or more. The number of signals and the HER2/ CEP17 ratio were first estimated on the tissue specimens of the TMA. The tumours that had an apparently normal ratio and those with an unequivocal amplification (dense clusters of HER2 signals or an estimated ratio of more than 2.5) were not analysed again. In the cytological specimens, the ratio was calculated on the basis of 60 scored cells in most cases. In 14 $(13 \%)$ of the cytological specimens fewer than 60 tumour cells were available for FISH analysis (range 6 to 59 cells).

Cases with a discrepant HER2 result between the primary tumour and the metastases were scored again, and at least 20 cells were counted for confirmation. In addition, a routine tissue section of the original donor block was analysed by FISH in discrepant cases in which the primary tumour was represented on the tissue microarray. Thus, a possible sampling bias due to the small size of the TMA cores could be excluded.

\section{Statistical analysis}

The rate of concordance between the primary tumour and metastatic tumour was analysed with the kappa coefficient ( $\kappa)$. A value of $\kappa>0.8$ suggests an 'excellent' concordance in amplification status between the two tumour sites, whereas a $\kappa$ value between 0.61 and 0.8 indicates 'substantial' agreement. Contingency table analysis was applied to calculate the association between pT category, pN category, nuclear grade and HER2 FISH status. Analysis of variance (ANOVA) or Student's $t$ test was applied to determine the parameters with greatest influence on the time to metastasis. The level of statistical significance was set at $p \leq 0.05$ two-sided), and all statistical calculations were performed with JMP 3.0 software (SAS Institute Inc., Cary, NC, USA).

\section{Results}

The HER2 status of the primary breast cancers and the matched metastases was concordant in $92.4 \%$ of the 105 
patients at the time of the initial evaluation $(\kappa=0.76$; $95 \%$ confidence interval $(\mathrm{Cl}) 0.61$ to 0.92$)$. This substantial concordance was increased to $97.1 \%$ after re-evaluation of all discordant cases $(\kappa=0.85 ; 95 \% \mathrm{Cl}=0.73$ to 0.98 ).

HER2 amplification was found in 22 (21\%) of the 105 primary tumours and in $21(20 \%)$ of the matched distant metastases. The HER2 status between primary tumours and distant metastases differed in eight (7.6\%) of the patients at the time of the initial evaluation.

The primary tumours of all eight discrepant cases were reanalysed on routine tissue sections, and the hybridised cytological specimens were carefully scored again. On the routine tissue sections we calculated an exact ratio from at least 20 scored cells. The clinicopathological characteristics and FISH findings of these patients are summarised in Table 3.

Re-evaluation showed that in one patient with HER2 amplification of the primary tumour, rare tumour cells with HER2 amplification in the pleural effusion had been overlooked as a result of rarity of malignant cells and a highly predominating background of reactive mesothelial cells and macrophages (Figure $1 \mathrm{a}, \mathrm{b})$. In another patient, tumour cells in the pleural effusion but not on the TMA specimen of the primary tumour showed HER2 amplification. However, FISH on the routine tissue section of the primary tumour revealed a heterogeneous HER2 status with only a few amplified tumour cells (Figure 1c,d).

In another patient, metastasis showed low-level gain but no amplification of the HER2 gene (HER2/CEP17 ratio 1.25, with 3 to $10 / 4$ to 6 signals), whereas the primary tumour had initially been scored as amplified on the TMA spot. Routine section FISH analysis of the primary tumour also revealed low- level gain with a HER2/CEP17 ratio of 1.6 (with 1 to $2 / 2$ to 6 signals). A further two patients had a 'borderline' amplification. One patient had an average HER2/CEP17 ratio of 2.1 (with 3 to $9 / 2$ to 4 signals) in the primary tumour but a ratio of only 1.38 in the metastasised cells of the peritoneal effusion (with 3 to $23 / 3$ to 15 signals). The other patient had a HER2/ CEP17 ratio of 2.1 , with 2 to $8 / 2$ signals after repeated counting of 20 tumour cells, whereas the metastatic cells had a ratio of 1.69 (5 to $10 / 3$ to 6 signals).

Three patients $(2.9 \%)$ remained with an unexplained discrepancy even after re-evaluation of the cytological specimens and repeated $\mathrm{FISH}$ analysis of the routine tissue sections of the primary tumour (Figure 1e,f). Two of the patients had a primary tumour with a normal copy number of HER2 and chromosome 17 but with HER2 amplification in the metastasis. The other patient had high-level amplification with a ratio of more than 3 in the primary tumour ( 10 to $20 / 2$ to 4 ), in contrast with a ratio of 1.83 (3 to $6 / 2$ to 3 ) in the metastasis.

HER2 amplification was significantly associated with nuclear grade but not with $\mathrm{pT}$ and $\mathrm{pN}$ category (Table 4). Time from resection of the primary tumour to the diagnosis of metastases was not significantly associated with the pT category $(p=$ $0.248)$, the $\mathrm{pN}$ category $(p=0.1383)$ or the nuclear grade $(p$ $=0.3777$; detailed data not shown). Metastases tended to occur earlier in tumours with HER2 amplification than in those without (44.1 \pm SEM 7.8 months versus 71.8.6 \pm SEM 7.3 months; $p=0.0639)$.

The whole metastatic cascade from primary tumour to axillary lymph node metastasis and distant metastasis was analysed in 31 patients (29.5\%). One patient with discordant HER2 status between the primary tumour (HER2/CEP17 ratio 2.1) and

Table 3

Clinicopathological characteristics and discrepant HER2 FISH status between primary tumour and distant metastasis

\begin{tabular}{|c|c|c|c|c|c|c|c|c|}
\hline \multirow[t]{2}{*}{ Case no. } & \multirow[t]{2}{*}{ Age (years) } & \multicolumn{4}{|c|}{ Clinicopathological characteristics } & \multicolumn{3}{|l|}{ HER2 status } \\
\hline & & Tumour size $(\mathrm{cm})$ & Histology & Grade $^{a}$ & Metastatic & Metastases & Primary tumour & Explanation ${ }^{b}$ \\
\hline 1 & 34 & 1.0 & Ductal & 3 & Pleura & Amplified & Negative & True discrepancy \\
\hline 2 & 52 & Not available & Ductal & 3 & Cerebrospinal fluid & Amplified & Negative & True discrepancy \\
\hline 3 & 65 & 2.5 & Ductal & 3 & Pleura & Amplified & Negative & True amplification \\
\hline 4 & 52 & 1.6 & Ductal & 3 & Pleura & Negative & Amplified & True amplification \\
\hline 5 & 47 & 1.8 & Ductal & 3 & Ascites & Negative & Amplified & Borderline \\
\hline 6 & 47 & Not available & Ductal & 3 & Pleura & Negative & Amplified & True amplification \\
\hline 7 & 82 & 5.2 & Ductal & 2 & Pleura & Negative & Amplified & Borderline \\
\hline 8 & 62 & 2.5 & Ductal & 3 & Lung & Negative & Amplified & True negative \\
\hline
\end{tabular}

HER2, gene encoding human EGF-like receptor 2; FISH, fluorescence in situ hybridization; true discrepancy, discrepancy remained unexplained; true amplification, amplification was found both in the metastasis and in the primary tumour after review; true negative, amplification was not confirmed after review; borderline, discrepancy was explained by interpretational difficulty due to a HER2/CEP17 ratio close to the threshold of 2 or less. aNuclear grade (1 to 3$)$; bexplanations for the discrepancies of HER2 status. 
Figure 1
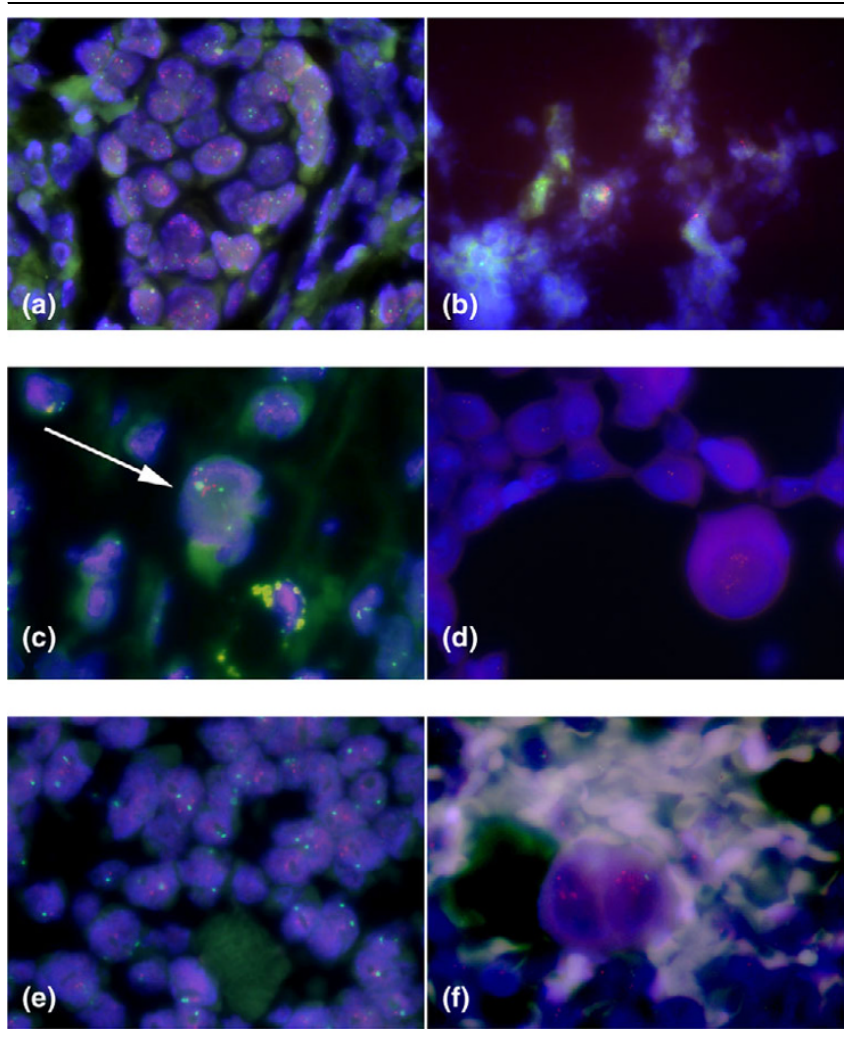

Examples of discrepancies of HER2 FISH status between primary breast cancers and matched distant metastases. HER2 (gene encoding human EGF-like receptor 2) fluorescence in situ hybridisation (FISH) status on histological specimens (a, c, e) and matched cytologies of distant metastases $(b, d, f)$. (a, b) Discrepancy due to interpretational difficulty. High-level amplification in primary tumour (a), and rare amplified metastatic cells in pleura effusion that had been overlooked (b). (c, d) Discrepancy due to heterogeneity. Rare tumour cells (arrow) with amplification in the primary breast cancer (c), and metastatic cells in pleural effusion with amplification (d). (e, f) True discrepancy. HER2negative primary breast cancer (e), and amplification in metastatic cells (f). Original magnifications $\times 630$ to 1,000 .

the distant metastasis (HER2/CEP17 ratio 1.38) had a 'borderline result' in the lymph node (HER2/CEP17 ratio 1.9). There was complete concordance of the FISH results in the remaining 30 cases, 4 of which showed amplification.

\section{Discussion}

HER2 amplification identifies patients who are likely to respond to therapy with trastuzumab, a humanised antibody directed against the HER2 protein [27,28]. Approval of trastuzumab was originally restricted to patients with HER2-positive metastatic disease. On the basis of the positive results of recent international trials [12], approval is now being extended internationally to adjuvant treatment of HER2-positive breast cancers. In the mean time, HER2 analysis of all newly diagnosed breast cancers has already become a standard in many institutions. Because of the high costs of trastuzumab and the risk of cardiotoxicity in some patients [29], it is crucial to make a precise selection of patients for treatment to guarantee optimal clinical benefit while retaining cost effectiveness.

In patients with metastatic disease, selection for therapy with trastuzumab has traditionally been based on the HER2 status of the primary tumour. The reported prevalence of discordance of HER2 status between primary tumour and metastasis ranges from 0 to $22.2 \%$ when assessment with both immunohistochemistry and FISH is considered [20,21,23,30]. Part of these discrepancies is likely to be due to the well-known technical and interpretational limitations of immunohistochemical HER2 assessment [13,15,31]. Because FISH is considered the gold standard for HER2 testing [32,33], we investigated the discordance rate based solely on FISH in a large consecutive series of metastatic breast cancers. We found a discrepancy in $8(7.6 \%)$ of the 105 patients. This is in the range of previous studies with FISH and confirms considerable stability of HER2 gene status even in tumours that developed distant metastases more than 21 years after initial surgery (Table 5) $[19,21]$. The discrepancies included three tumours with positive primaries but negative metastases, as determined by $\mathrm{FISH}$, and five positive metastases but negative primaries. There would therefore be a risk of both undertreatment and overtreatment of these metastasised breast cancers if the treatment decision were based only on the HER2 status of these primary tumours.

The reasons for discrepancy in HER2 FISH status between primary breast cancer and metastases have not been investigated in previous studies. Here, detailed re-evaluation of the HER2 FISH status by scoring the specimens again or by hybridising routine tissue sections allowed us to discover reasons for HER2 discrepancies. Not all discrepant results represented true biological conversion. Instead, we uncovered interpretational difficulties as a reason in five (4.7\%) of the patients. One had a slight gain of HER2 signals that was regarded as amplified in the first evaluation. In two patients, the discrepancy was explained by a HER2/reference ratio that was slightly lower or higher than the threshold of 2 , which we refer to as 'borderline'. It is conceivable that such a borderline ratio is more prone to inter-observer variation than amplification with a high ratio or dense gene clusters. In a recent interlaboratory survey, there was a considerable variability in interpretation of cases with low-level or borderline amplification [34]. In contrast, those authors found excellent reproducibility in HER2 FISH analysis for tumours with no amplification or high amplification of the HER2 gene. This highlights the need for consensus on the use of an equivocal/borderline interpretative category. Accordingly, the package insert of the PathVysion includes the statement 'a ratio at or near the cutoff ( 1.8 to $2.2)$ should be interpreted with caution'. The clinical relevance of this type of interpretational limitation is not clear, because the impact of the ratio level on the likelihood of therapy response is still unknown. One could hypothesise that the 
Breast Cancer Research Vol 9 No 3 Tapia et al.

Table 4

Comparison between HER2 amplified and non-amplified primary breast cancers

\begin{tabular}{|c|c|c|c|}
\hline Characteristic & $n$ amplified (percentage) & $n$ not amplified (percentage) & $p$ \\
\hline \multicolumn{4}{|l|}{ pT category } \\
\hline pT1 & $3(10.3)$ & $26(89.7)$ & 0.31 \\
\hline pT2 & $13(26.5)$ & $36(73.5)$ & \\
\hline pT3 & $2(28.6)$ & $5(71.4)$ & \\
\hline pT4 & $2(14.3)$ & $12(85.7)$ & \\
\hline Not available & 2 (33.3) & $4(66.7)$ & \\
\hline \multicolumn{4}{|l|}{ Nodal status } \\
\hline Positive & $14(21.9)$ & $50(78.1)$ & 0.44 \\
\hline Negative & $4(14.8)$ & $23(85.2)$ & \\
\hline Not available & $4(28.6)$ & $10(71.4)$ & \\
\hline \multicolumn{4}{|l|}{ Histologal type } \\
\hline Ductal & $20(24.4)$ & $62(75.6)$ & 0.30 \\
\hline Lobular & $2(16.7)$ & $10(83.3)$ & \\
\hline Ductulo-lobular & 0 & $10(100)$ & \\
\hline Medullary & 0 & $1(100)$ & \\
\hline \multicolumn{4}{|l|}{ Nuclear grade } \\
\hline 1 & 0 & $7(100)$ & 0.01 \\
\hline 2 & $4(9.8)$ & $37(90.2)$ & \\
\hline 3 & $18(32.7)$ & $37(67.3)$ & \\
\hline Not available & 0 & $2(100)$ & \\
\hline
\end{tabular}

HER2, gene encoding human EGF-like receptor 2 .

response rate is low in breast cancers with a borderline FISH result.

Rarity of HER2 amplified cells was responsible for a discrepancy in a further two patients. In one of these, rare HER2amplified cells were initially overlooked on a cytological smear from metastasis with a high background of reactive cells. In the other patient, rare amplified cells were not detected initially because of intratumoral heterogeneity of HER2 status within the primary tumour. In this patient, we must assume the presence of clonal selection of the rare HER2-amplified cells in the primary for distant metastatic spread. Our finding also emphasises the importance of careful and thorough evaluation of the hybridised specimens, because heterogeneity with small cancer foci prevails in rare cases $[35,36]$.

In three of the eight patients (patients 1, 2, and 8 in Table 3) we could not identify any interpretational reason for the discrepancy. Two of these were negative, as determined by $\mathrm{FISH}$, in the primary but positive in the metastasis. In the third tumour, high-level amplification in the primary contrasted with low-level gain in the metastasis. It is possible that these three tumours represented true conversion of HER2 status by clonal selection or genetic drift during metastatic progression. However, we cannot exclude the possibility of undetected heterogeneity even in these cases, because only a small percentage of the entire tumour volume is represented on a histological section or on a cytological smear [37,38].

The patients of this study were selected on the basis of the availability of cytologically diagnosed distant metastases. Fineneedle aspiration cytology of solid lesions or exfoliative cytology (for example malignant effusions) is a commonly used method to diagnose or confirm metastatic disease. Our results confirm that cytological specimens are well suited to HER2 FISH analysis $[22,39,40]$. It has previously been shown that results of HER2 FISH analyses from cytological specimens are highly concordant with matched histological sections $[41,42]$. It is therefore unlikely that our results were affected by the different types of tumour material of primary tumours and metastases.

The standard morphological parameters (pT category, pN category and grade) are strong prognostic factors in newly diagnosed breast cancer [43]. Interestingly, none of these parameters was significantly associated with the time interval 
Fluorescence in situ hybridisation studies comparing primary breast cancers and their matched distant metastases

\begin{tabular}{lllll}
\hline Reference & $n$ & $\begin{array}{l}\text { Discordance between metastases and } \\
\text { primary tumours (percentage) }\end{array}$ & $\begin{array}{l}\text { Number of HER2-positive primary } \\
\text { tumours }\end{array}$ & Number of HER2-positive metastases \\
\hline$[23]$ & 12 & 0 & 12 & 12 \\
{$[20]$} & 68 & 7.0 & 2 & 3 \\
{$[22]$} & 14 & 0 & 14 & 14 \\
{$[21]$} & 18 & 22.2 & 3 & 7 \\
{$[19]$} & 17 & 6.0 & Not available & Not available \\
This study & 105 & 7.6 & 21 & 20 \\
\hline
\end{tabular}

HER2, gene encoding human EGF-like receptor 2.

from initial treatment to cytological diagnosis of distant metastasis in our selected series of patients. Because the time of cytological sampling of metastatic cells is not always identical with the time of first clinical detection of metastasis, prognostic data must be interpreted with caution in our study. Nevertheless, our data indicate that within the group of breast cancers that are capable of distant metastasis, the dynamics of metastasis is driven by biological or environmental factors that are not fully reflected by morphological features. The observed tendency of HER2 amplification towards early metastasis is concordant with the known adverse prognostic role of HER2 amplification [44].

\section{Conclusion}

HER2 FISH status is highly preserved as breast cancers progress to metastatic disease. However, a discrepancy in HER2 status exists in a small fraction of patients. As well as true conversion of HER2 status, interpretational difficulties due to borderline FISH results, rarity of tumour cells and intratumoral heterogeneity were identified as important reasons for the discrepancy. Irrespective of the reason, however, every discordance in HER2 status is a diagnostic reality and can lead to inaccurate treatment decisions with medical and economical effects. To guarantee optimal care of individual patients, we advocate HER2 analysis of distant metastases in all patients irrespective of the result in the primary tumour. The feasibility of this approach will ultimately be determined by economic factors. Future patients with distant metastases after adjuvant treatment for HER2-positive breast cancer will pose additional diagnostic and therapeutic challenges. It is possible that treatment with trastuzumab leads to clonal selection of HER2-negative tumour cells, as observed in individual patients [35]. Thus, HER2 testing of metastasis may become a necessity in every patient.

\section{Competing interests}

LB has received speaker's honorarium and refunding of travel costs, and research funding from Abbott Molecular Inc. CT has received refunding of travel costs by Abbott Molecular Inc.
All other authors declare that they do not have competing interests.

\section{Authors' contributions}

CT contributed to the study design, was responsible for statistical evaluation and drafted the manuscript. SS participated in study design and FISH evaluation. UW, RS and GC selected and provided matched specimens. $H N$ performed and scored FISH on the histological specimens. BG, MH and BDV performed and scored FISH on the cytological specimens. IZ performed statistical analyses. LT was responsible for and supervised FISH on the histological specimens. GF was involved in evaluation of the cytological specimens. LB conceived the study, supervised the experiments, revised the manuscript critically for important intellectual content and gave final approval of the version to be published. All authors read and approved the final manuscript.

\section{References}

1. Di Fiore PP, Pierce JH, Kraus MH, Segatto O, King CR, Aaronson SA: erbB-2 is a potent oncogene when overexpressed in NIH/ 3T3 cells. Science 1987, 237:178-182.

2. Kauraniemi $P$, Kallioniemi A: Activation of multiple cancer-associated genes at the ERBB2 amplicon in breast cancer. Endocr Relat Cancer 2006, 13:39-49.

3. Rajkumar T, Gullick WJ: The type I growth factor receptors in human breast cancer. Breast Cancer Res Treat 1994, 29:3-9.

4. Hanna W, Kahn HJ, Trudeau M: Evaluation of HER-2/neu (erbB2) status in breast cancer: from bench to bedside. Mod Pathol 1999, 12:827-834.

5. Zhang D, Salto-Tellez M, Do E, Putti TC, Koay ES: Evaluation of HER-2/neu oncogene status in breast tumors on tissue microarrays. Hum Pathol 2003, 34:362-368.

6. De Potter CR, Schelfhout AM: The neu-protein and breast cancer. Virchows Arch 1995, 426:107-115.

7. Slamon DJ, Clark GM, Wong SG, Levin WJ, Ullrich A, McGuire WL: Human breast cancer: correlation of relapse and survival with amplification of the HER-2/neu oncogene. Science 1987, 235:177-182.

8. Plosker GL, Keam SJ: Trastuzumab: a review of its use in the management of HER2-positive metastatic and early-stage breast cancer. Drugs 2006, 66:449-475.

9. Baselga J, Tripathy D, Mendelsohn J, Baughman S, Benz CC, Dantis L, Sklarin NT, Seidman AD, Hudis CA, Moore J, et al.: Phase II study of weekly intravenous trastuzumab (Herceptin) in patients with HER2/neu-overexpressing metastatic breast cancer. Semin Oncol 1999, 26:78-83.

10. Leyland-Jones B: Trastuzumab: hopes and realities. Lancet Oncol 2002, 3:137-144. 
11. Tripathy D, Slamon DJ, Cobleigh M, Arnold A, Saleh M, Mortimer JE, Murphy M, Stewart SJ: Safety of treatment of metastatic breast cancer with trastuzumab beyond disease progression. J Clin Oncol 2004, 22:1063-1070.

12. Tuma RS: Trastuzumab trials steal show at ASCO meeting. J Natl Cancer Inst 2005, 97:870-871.

13. Press MF, Hung G, Godolphin W, Slamon DJ: Sensitivity of HER2/neu antibodies in archival tissue samples: potential source of error in immunohistochemical studies of oncogene expression. Cancer Res 1994, 54:2771-2777.

14. Pauletti G, Dandekar S, Rong H, Ramos L, Peng H, Seshadri R, Slamon DJ: Assessment of methods for tissue-based detection of the HER-2/neu alteration in human breast cancer: a direct comparison of fluorescence in situ hybridization and immunohistochemistry. J Clin Oncol 2000, 18:3651-3664.

15. Tapia C, Schraml P, Simon R, Al-Kuraya KS, Maurer R, Mirlacher M, Novotny H, Spichtin H, Mihatsch MJ, Sauter G: HER2 analysis in breast cancer: reduced immunoreactivity in FISH noninformative cancer biopsies. Int J Onco/ 2004 25:1551-1557.

16. Mass RD, Press MF, Anderson S, Cobleigh MA, Vogel CL, Dybdal $\mathrm{N}$, Leiberman $\mathrm{G}$, Slamon DJ: Evaluation of clinical outcomes according to HER2 detection by fluorescence in situ hybridization in women with metastatic breast cancer treated with trastuzumab. Clin Breast Cancer 2005, 6:240-246.

17. Press MF, Sauter G, Bernstein L, Villalobos IE, Mirlacher M, Zhou JY, Wardeh R, Li YT, Guzman R, Ma Y, et al: : Diagnostic evaluation of HER-2 as a molecular target: an assessment of accuracy and reproducibility of laboratory testing in large, prospective, randomized clinical trials. Clin Cancer Res 2005, 11:6598-6607.

18. Gokhale S, Gatalica Z, Mohammad A, Rampy Al, Velagaleti Gopalrao VN: FISH for HER-2/neu in breast cancer: standardization makes the difference! Indian J Cancer 2004, 41:152-158.

19. Gong $Y$, Booser DJ, Sneige N: Comparison of HER-2 status determined by fluorescence in situ hybridization in primary and metastatic breast carcinoma. Cancer 2005, 103:1763-1769.

20. Gancberg D, Di Leo A, Cardoso F, Rouas G, Pedrocchi M, Paesmans $M$, Verhest A, Bernard-Marty C, Piccart MJ, Larsimont D: Comparison of HER-2 status between primary breast cancer and corresponding distant metastatic sites. Ann Oncol 2002, 13:1036-1043.

21. Regitnig $P$, Schippinger $W$, Lindbauer $M$, Samonigg $H$, Lax SF: Change of HER-2/neu status in a subset of distant metastases from breast carcinomas. J Pathol 2004, 203:918-926.

22. Bozzetti C, Personeni N, Nizzoli R, Guazzi A, Flora M, Bassano C, Negri F, Martella E, Naldi N, Franciosi V, et al.: HER-2/neu amplification by fluorescence in situ hybridization in cytologic samples from distant metastatic sites of breast carcinoma. Cancer 2003, 99:310-315.

23. Tanner $M$, Jarvinen $P$, Isola J: Amplification of HER-2/neu and topoisomerase Il $\alpha$ in primary and metastatic breast cancer. Cancer Res 2001, 61:5345-5348.

24. Elston CW, Ellis IO: Pathological prognostic factors in breast cancer. I. The value of histological grade in breast cancer: experience from a large study with long-term follow-up. Histopathology 1991, 19:403-410.

25. Kononen J, Bubendorf L, Kallioniemi A, Barlund M, Schraml P Leighton S, Torhorst J, Mihatsch MJ, Sauter G, Kallioniemi OP: Tissue microarrays for high-throughput molecular profiling of tumor specimens. Nat Med 1998, 4:844-847.

26. Goldhirsch A, Glick JH, Gelber RD, Coates AS, Thurlimann B, Senn HJ: Meeting highlights: international expert consensus on the primary therapy of early breast cancer 2005. Ann Oncol 2005, 16:1569-1583.

27. Ross JS, Fletcher JA, Bloom KJ, Linette GP, Stec J, Symmans WF, Pusztai L, Hortobagyi GN: Targeted therapy in breast cancer: the HER-2/neu gene and protein. Mol Cell Proteomics 2004, 3:379-398.

28. Di Leo A, Dowsett M, Horten B, Penault-Llorca F: Current status of HER2 testing. Oncology 2002, 63:25-32.

29. Cobleigh MA, Vogel CL, Tripathy D, Robert NJ, Scholl S, Fehrenbacher L, Wolter JM, Paton V, Shak S, Lieberman G, et al.: Multinational study of the efficacy and safety of humanized antiHER2 monoclonal antibody in women who have HER2-overexpressing metastatic breast cancer that has progressed after chemotherapy for metastatic disease. J Clin Oncol 1999, 17:2639-2648.

30. Simon R, Nocito A, Hubscher T, Bucher C, Torhorst J, Schraml P, Bubendorf L, Mihatsch MM, Moch H, Wilber K, et al:: Patterns of her-2/neu amplification and overexpression in primary and metastatic breast cancer. J Natl Cancer Inst 2001, 93:1141-1146.

31. Bilous M, Dowsett M, Hanna W, Isola J, Lebeau A, Moreno A Penault-Llorca F, Ruschoff J, Tomasic G, van de Vijver M: Current perspectives on HER2 testing: a review of national testing guidelines. Mod Pathol 2003, 16:173-182.

32. Elkin EB, Weinstein MC, Winer EP, Kuntz KM, Schnitt SJ, Weeks JC: HER-2 testing and trastuzumab therapy for metastatic breast cancer: a cost-effectiveness analysis. J Clin Oncol 2004, 22:854-863.

33. Gong Y, Gilcrease M, Sneige N: Reliability of chromogenic in situ hybridization for detecting HER-2 gene status in breast cancer: comparison with fluorescence in situ hybridization and assessment of interobserver reproducibility. Mod Patho/ 2005 , 18:1015-1021.

34. Persons DL, Tubbs RR, Cooley LD, Dewald GW, Dowling PK, Du E, Mascarello JT, Rao KW, Wilson KS, Wolff DJ, et al.: HER-2 fluorescence in situ hybridization: results from the survey program of the College of American Pathologists. Arch Pathol Lab Med 2006, 130:325-331.

35. Kunitomo K, Inoue S, Ichihara F, Kono K, Fujii H, Matsumoto Y, Ooi A: A case of metastatic breast cancer with outgrowth of HER2negative cells after eradication of HER2-positive cells by humanized anti-HER2 monoclonal antibody (trastuzumab) combined with docetaxel. Hum Pathol 2004, 35:379-381.

36. Sekido Y, Umemura S, Takekoshi S, Suzuki Y, Tokuda Y, Tajima T, Osamura RY: Heterogeneous gene alterations in primary breast cancer contribute to discordance between primary and asynchronous metastatic/recurrent sites: HER2 gene amplification and p53 mutation. Int J Oncol 2003, 22:1225-1232.

37. Shin SJ, Hyjek E, Early E, Knowles DM: Intratumoral heterogeneity of her-2/neu in invasive mammary carcinomas using fluorescence in-situ hybridization and tissue microarray. Int J Surg Pathol 2006, 14:279-284.

38. Moriki T, Takahashi T, Ueta S, Mitani M, Ichien M: Hormone receptor status and HER2/neu overexpression determined by automated immunostainer on routinely fixed cytologic specimens from breast carcinoma: correlation with histologic sections determinations and diagnostic pitfalls. Diagn Cytopatho/ 2004 30:251-256

39. Sauter G, Feichter G, Torhorst J, Moch H, Novotna H, Wagner U Durmuller U, Waldman FM: Fluorescence in situ hybridization for detecting erbB-2 amplification in breast tumor fine needle aspiration biopsies. Acta Cytol 1996, 40:164-173.

40. Nizzoli R, Guazzi A, Naldi N, Fraciosi V, Bozzetti C: HER-2/neu evaluation by fluorescence in situ hybridization on destained cytologic smears from primary and metastatic breast cancer. Acta Cytol 2005, 49:27-30.

41. Bozzetti C, Nizzoli R, Guazzi A, Flora M, Bassano C, Crafa P, Naldi N, Cascinu S: HER-2/neu amplification detected by fluorescence in situ hybridization in fine needle aspirates from primary breast cancer. Ann Oncol 2002, 13:1398-1403.

42. Gu M, Ghafari S, Zhao M: Fluorescence in situ hybridization for HER-2/neu amplification of breast carcinoma in archival fine needle aspiration biopsy specimens. Acta Cytol 2005 49:471-476

43. Fitzgibbons PL, Page DL, Weaver D, Thor AD, Allred DC, Clark GM, Ruby SG, O'Malley F, Simpson JF, Connolly JL, et al.: Prognostic factors in breast cancer. College of American Pathologists Consensus Statement 1999. Arch Pathol Lab Med 2000, 124:966-978.

44. Ross JS, Fletcher JA, Linette GP, Stec J, Clark E, Ayers M, Symmans WF, Pusztai L, Bloom KJ: The Her-2/neu gene and protein in breast cancer 2003: biomarker and target of therapy. Onco/ogist 2003, 8:307-325. 